\title{
Até quando a Disciplina de Físico-Químicas nos Planos curriculares do Ensino Básico e Secundário?
}

\author{
A. CORREIA CARDOSO*
}

"Se eu tivesse hoje, em Outubro de 1993, que desenhar alguns aspectos da reforma curricular, da gestão, da própria lei das bases ou da formação de professores, fá-lo-ia com certeza de forma substancialmente diferente da que está hoje a ser implementada Não porque seja um catavento e esteja a mudar de ideias todos os dias, mas porque a dinâmica cultural, económica e institucional é hoje de tal forma que não se compadece com uma reforma que dura dez anos" (Roberto Carneiro, ex-ministro da Educação, "Público" edição de 24/10/93).

1. A pouco tempo da generalização dos novos programas da componente de Química da disciplina de Físico-Químicas ( $8^{\circ}$ e $10^{\circ}$ anos, no próximo ano lectivo) a situação existente é, no minimo, preocupante face às expectativas criadas. Por um lado, grande número de professores continuam a desconhecer os programas. Os poucos que os conhecem sentem dificuldades em acompanhar as mudanças. Os que já há algum tempo o têm ensinado na sua fase experimental acumulam rotinas ${ }^{\star \star}$. Por outro lado, dá-se conta que programas já em fase de generalização, designadamente do $5^{\circ}$ e $6^{\circ}$ anos do $2^{\circ}$ ciclo de Ciências da Natureza e do $8^{\circ}$ ano do $3^{\circ}$ ciclo da disciplina de Ciências Naturais do ensino básico, $\mathrm{EB}$, desenvolvem conteúdos químicos que, grosso modo, ultrapassam $50 \%$ dos que constituem os novos programas do $8^{\circ} \mathrm{e} 9^{\circ}$ anos de Química, remetendo esta para uma disciplina revestida de características académicas, como tem sido tradicional.

Perante um tal quadro, pressentem-se obstáculos ao desenvolvimento dos programas da componente de Química principalmente a nível do $8^{\circ}$ e $9^{\circ}$ anos do $3^{\circ}$ ciclo do EB.

A disciplina de Físico-Química, a este nivel, prossegue três dimensões gerais: a "dimensão pessoal", a "dimensão das aquisições básicas e intelectuais fundamentais" e a "dimensão para a cidadania". Qual a abordagem a tomar, em termos de adequabilidade aos novos programas de Química, de modo a garantir a integração das dimensões referidas? A resposta não é fácil. Existem diversos factores impeditivos ${ }^{\star \star *}$. Destacamos 0 que se prende com a grande preocupação, em qualquer dos programas, na articulação com a Física com a qual a
Química tem sem dúvida algumas ligações de oportunidades, mas minimizando-se as ligações cada vez mais importantes da Química às Ciências da Terra e da Vida.

Aliás a falta de articulação entre a Química e as Ciências da Natureza e Ciências Naturais a nivel do $E B$ e as Ciências da Terra e da Vida a nivel secundário, ES, foi um dos maiores problemas com que os respectivos professores se debateram nos programas anteriores. Damos conta que continua a manter-se, agravando-se mesmo, nos programas em implementação.

Atente-se em dois exemplos respigados de manuais, com base nos novos programas, de Ciências da Natureza do $5^{\circ}$ e $6^{\circ}$ anos do EB.
0 exemplo integra-se no Tema: $A$ água, 0 ar, as rochas e 0 solo - materiais terrestres, suportes da vida.... A água como solvente. Diversidade de materiais dissolvidos na água.

Não há qualquer objecção a referencia, a este nivel, dos termos "solução", "soluto", "substâncias solúveis e insolúveis". Contudo, quando se passa à respectiva aplicação, parece-nos não ser conveniente 0 tipo de actividade como a referida. Fala-se de "substâncias" dissolvidas, na importância de "elementos" para concluir sobre a diversidade de "materiais" que se dissolvem na água. Uma grande confusão! É bem sabido que o rótulo refere as espécies iónicas correspondentes a compostos (sais) que se dissolvem em água (sódio e

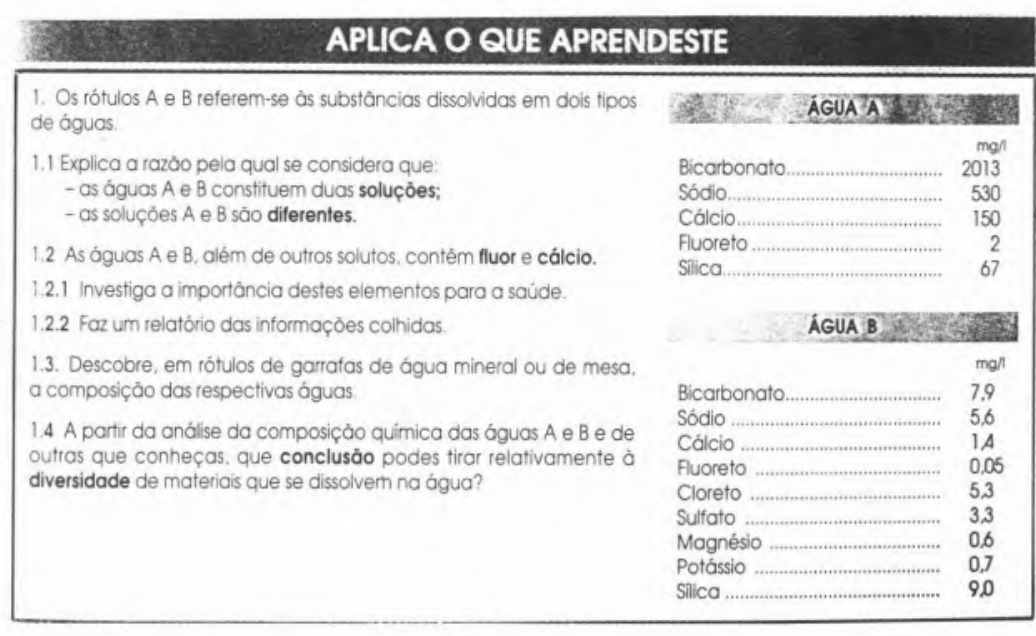

INVESTIGAÇÃO

MATERIAL

'tubos de ensaio, $A$ e B. água: ácido cloridrico; pepsina" comercial (extraida do suco gástrico); 2 bocados de arne da mesma qualidade e de tamanho semelhante

ROCEDIMENTO

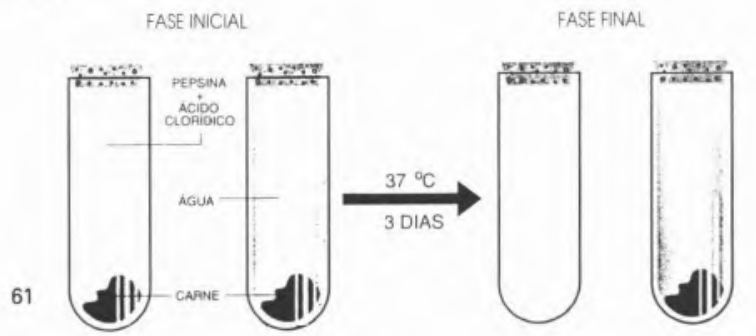


potássio numa garrafa de água!!!).

Termos como materiais, substâncias elementares e compostas, solução, soluto, solvente, a caracterização quantitativa de soluções particularmente em grama por $\mathrm{dm}^{3}$ de solução - os iões como unidades estruturais, fazem parte do programa de Química do $8^{\circ}$ ano.

0 segundo exemplo integra-se no Tema: Processos vitais comuns aos seres vivos. Trocas nutricionais entre 0 organismo e o meio com o objectivo de compreender que a vida dos seres e assegurada pela realização de funções específicas. Alimentos e vitaminas aparecem como termos/conceitos. não há qualquer referência explicita a hidratos de carbono, gorduras, proteínas e fibras. 0 desenvolvimento que se faz destes compostos (e outros) e respectivas transformações incluindo a aplicação é, na nossa opinião, exagerado.

Aliás este assunto é revisitado e extensamente aprofundado no $8^{\circ}$ ano do $3^{\circ}$ ciclo do EB na parte do programa referente a Energia e Vida: Os alimentos e a manutenção da vida.... A alimentação e saúde.... A fisiologia da digestão.

Apenas no programa do $9^{\circ}$ ano de Química se contempla o estudo simples dos compostos de carbono anteriormente referidos, assim como alguns testes de identificação.

A nivel do ES, a gestão da articulaçã̃o interdiciplinar e intradisciplinar - da componente de Química, que integra a disciplina de Físico - Químicas, ultrapassa a imaginação de Spielberg. Enquanto a Química inicia 0 estudo com a Quantidade em Química, as Ciências da Terra e da Vida inclui no Tema "Origem da Energia Produção e Mobilização de ATP" o Ciclo de Calvin (considerando a remoção de electrões da clorofila, fotólise da água, síntese de ATP e de NADHP, redução de $\mathrm{CO}_{2}$ ), 0 Ciclo de Krebs (considerando, por exemplo, a identificação dos intervenientes na reacção que conduz à síntese do ácido cítrico). A imaginação e também um factor em conta a respeito da intradisciplinaridade. A disciplina Técnicas Laboratoriais de Química (componente técnica dos cursos predominantemente orientados para prosseguimentos de estudos) desenvolve-se sem qualquer ligação à componente de formação específica. Paradoxalmente, o programa do $10^{\circ}$ ano de Química encontra-se em fase de consolidação enquanto que as Ténicas Laboratoriais já de generalização. ${ }^{1}$

A falta de integração ou de articulação é ainda agravada pelo facto de um grande número de professores identifica- rem o programa (que desconhecem) com 0 manual adoptado?

2. Pensamos que a existência hoje de uma disciplina, tanto a nivel do EB quer do ES, que associe a Física com a Química é bastante sustentada por razões de tradição e de formação de base de docentes que a leccionam. É tempo de começar a reflectir sobre a associação da Química, as Ciências da Terra e da Vida (e eventualmente a Fisica) em regime de integração a niveis do EB e articulação a nivel do ES. É tempo de rever 0 programa de formação de professores.

0 momento parece-nos adequado pois o ME prepara um projecto de redefinição das habilitaçōes para a docência no ES e ES. A documentação que nos tem chegado merece-nos alguns comentários.

É o caso, por exemplo, do $4^{\circ}$ grupo do $2^{\circ}$ ciclo do ensino básico. Não é suficiente a existência de uma licenciatura em Matemática e Ciências da Natureza oferecida por algumas Escolas Superiores de Educação, ESE. Pensamos que continuar a mantê-Io indiviso é sujeitar professores a leccionarem uma disciplina para a qual apenas possuem uma formação rudimentar. Também é controverso o desdobramento dos grupos de Física e Química, só com a finalidade de passar a integrar, em ambos, licenciados em Física e Química oriundos da ESE ou das universidades "novas" tanto no EB como no ES, considerando-os mesmo com habilitação para a monodisciplina de Fisica e de Química do $12^{\circ}$ ano.

Parece-nos que a aprovação deste projecto terá 0 perigo de "cristalizar" perpetuamente opçōes cuja reformulação é urgente. É o caso, designadamente, das disciplinas de Físico-Química do $8^{\circ}$ e $9^{\circ}$ anos e Ciências Naturais do $7^{\circ}$ e $8^{\circ}$ anos do EB.

A leccionação integrada da Física+Química+Biologia+Geologia no EB está prevista na Lei das Bases do Sistema Educativo, LBSE. "Só o reconhecimento de os professores actuais não possuirem a formaçāo conveniente para leccionar todas

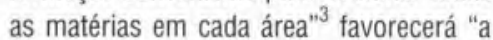
solução alternativa preconizada. "Nestas condiçōes, sem deixar de salientar a necessidade da revisão do programa de formação inicial de professores para estes domínios, aceita-se uma solução transitória próxima da actual, mas procurar-se-á assegurar uma articulação dos conteúdos programáticos de cada componente e aconselhando-se uma avaliação por área"4 .

No que respeita à configuração do ES, em termos de planos de estudos. defende-se, a partir do $10^{\circ}$ ano, o regime monodisciplinar, embora não contemplado na LBSE.

3. A reconversāo dos docentes existentes e a formação inicial dos futuros professores, na linha anteriormente referida, é matéria a redefinir com carácter prioritário. Estes problemas estão diagnosticados e apontadas possiveis soluções. ${ }^{5} 0$ que não podemos é continuar a assistir ao aparecimento de projectos cuja filosofia subjacente é "fazer qualquer coisa que 0 resto se adequará de seguida",

Hoje, com algum grau de ficção, inúmeros centros de formação produzem professores com habilitação para leccionar a disciplina de Fisico-Químicas (do EB e ES), curiosamente uma exclusividade dos planos curriculares portugueses, sob uma multiplicidade de designações - licenciatura em ensino da Fisica e Química (caso das universidades dos Açores, Aveiro, Évora, Minho, Trás-os-Montes e Alto Douro); ramo educacional da licenciatura em Física e Quimica (universidade do Algarve); licenciatura em ensino da Física (universidades da Beira Interior, Lisboa Faculdade de Ciências - Madeira); ramo de formação educacional da licenciatura em Física (universidades de Coimbra Faculdade de Ciências e Tecnologia Porto - Faculdade de Ciências); licenciatura em Quimica (universidade de Lisboa - Faculdade de Ciências, Madeira); ramo educacional da licenciatura em Química (universidades de Coimbra - Faculdade de Ciências e Tecnologia - Porto Faculdade de Ciências).

É bem verdade que "a formação de professores dos ensinos básico e secundário [...], sob pressão de um crescimento rápido do sistema educativo, que por acréscimo ocorreu em tempo de ruptura do sistema político, foi objecto de múltiplas medidas de recurso, que pouco a pouco se vão normalizando."

Admitindo um limite para este pressuposto temporal, reconhecemos certamente "logo que tal aconteça deverá fazerse uma reformulação de fundo, atribuindo maiores responsabilidades às Faculdades de Psicologia e às Escolas Superiores de Educação, com uma maior definição das funçōes destas últimas" ". Reconhece-se também que "os alunos que se preparam. nas Universidades, para exercer funções docentes nos ensinos básico e secundário devem inscrever-se nas Faculdades de Educaçâo, embora cursando as disciplinas de formação nos departamentos próprios $[\ldots]^{7}$. A questão é: Porque não se tomam 
as medidas adequadas, continuando a adiar 0 inadiável, reconhecendo-se antecipadamente e talvez unanimemente que "a dinâmica cultural, económica e institucional e hoje de tal forma que não se compadece com uma reforma de dez anos"?

4. Se é admissivel que a formação de professores has Universidades possa ser delegada a futuras Faculdades de Educação, sem minimizar a intervenção das Faculdades de Ciências (caso das universidades "clássicas"), já é menos admissivel que os respectivos departamentos não dinamizem "áreas de investigação no domínio do ensino pré-universitário e universitário". Aquela mudança ajuda a resolver, na minha opinião uma situação confusa. É que, ao retirar-se aos Departamentos o designado "Ramo Educacional" clarificam-se os parâmetros balizadores de tais áreas de investigação. A generalidade do termo "educacional", não tem permitido esta clarificação. Aqui tem cabido de tudo.

Porque se trata de educação "coisas que toda a gente se acha entendida e apta a discutir".

*Departamento de Química Universidade de Coimbra
* Co-autor dos programas de Química para o ensino básico e secundário.

** Atente-se que a fase experimental dos programas da componente de Química já percorreu 0 ciclo do $8^{\circ}$ ao $12^{\circ}$ anos. 0 atraso na generalização deve-se ao facto das versões inicialmente propostas para os programas relativos à componente de Física, não tendo sido inicialmente aprovados, haverem sofrido reformulações.

*** A. Correia Cardoso. "Centralidade do Trabalho Laboratorial nos Novos Programas de Química - Uma perspectiva de mudança". Plátano Editora. Lisboa. 1993, págs. 36-40.

${ }^{1} 0$ problema é idêntico com as Práticas Oficionais e Laboratoriais do $10^{\circ}$ ano do Curso Tecnológico de Química (componente técnica dos cursos predominantemente orientados para a vida activa).

${ }^{2}$ Nesta perspectiva não admira que estes materiais de apoio sejam normalmente elaborados tendo em vista simultaneamente alunos e professor. Mas apenas são úteis ao professor. Numa análise aos livros em circulação, já segundo os novos programas, dá-se conta que o número de páginas se situa entre 250-300, o que, para jovens com 0 nivel étário dos que frequentam $02^{\circ}$ e $3^{\circ}$ ciclos do EB, é "muita página". A resposta é conhecida: os alunos adquirem no início do ano lectivo o livro aconselhado. "passeiam-no" mas pouco ou nada 0 utilizam.

3"'Proposta de Reorganização dos Planos Curriculares dos Ensinos Basico e Secundário.

Relatório Final (1ª e $2^{2}$ Fases). Grupo de Trabalho: J.J. Fraústo da Silva, Manuel Tavares Emídio e Eduardo Marçalo Grilo

${ }^{4}$ Idem. 0 itálico é da nossa responsabilidade.

${ }^{5}$ Ver por exemplo Vitor Crespo "Uma Universidade para os anos $2000-0$ Ensino Superior numa perspectiva de futuro". Editorial Inquérito. Lisboa. 1993.

${ }^{6}$ Idem pág. 138. Sublinhado nosso.

${ }^{7}$ Idem pág. 139.

\section{MAGNETROM}

Desde 1967

26 Anos ao Serviço da Investigação e Indústria

Aparelhagem de Instrumentação e Controlo

Equipamento de Aquisição e Controlo

Representantes exclusivos da

$E G \& G$ / PAR

MAGNETROM - COMÉRCIO E INDÚSTRIA DE APARELHAGEM ELÉCTRICA, S.A.

Rua Fialho de Almeida, 5-2ํㅡ. Dt. - 1000 LISBOA

Tel. 3871918

Fax. 3874773 